\title{
THE PRESENTATION AND RECOGNITION OF SCHIZOPHRENIA IN A SERVICE SETTING
}

\author{
Major G. W. THOMPSON, D.P.M., R.A.M.C. \\ Assistant Professor of Army Psychiatry, Royal Army Medical College
}

\section{Introduction}

Ar the present time there is a tendency to deplore the specialisation of hospital medicine, yet at the same time to recognise that the general practitioner, who is concerned with a wider range of medicine, lacks opportunities and time for post-graduate training to keep abreast of advances in the medical specialities. General practitioners are intimately involved with the bulk of mental illness in the country, and Vickers (1965) has summarised this relationship between psychiatry and general practice. The teaching of psychiatry in medical schools has been repeatedly criticised and the lack of practical experience, with reliance upon lecture courses and out-patient demonstrations, has been emphasised by Hill (1963). The proportion of psychological medicine is increasing in Final examinations, but students whose psychiatric training falls in the latter part of their curriculum may prefer to spend their time revising other medical disciplines.

Thus as a result of incomplete training, inadequate practical experience and poor post-graduate facilities doctors may have experience only of classical presentations and text-book descriptions of psychotic illness; the correct diagnosis may not be suspected in atypical or insidious cases. This opinion is lent some support by the present survey in which it was found that only one in four schizophrenic patients treated at the Royal Victoria Hospital, Netley had been correctly diagnosed by the non-specialist medical officer who first saw the case. In many referring medical summaries the doctor was clearly puzzled, perplexed and unable to formulate a clear opinion.

This paper is intended as a help to unit medical officers and casualty officers and a guide to the ways in which schizophrenia can present in disguised form. As in other illnesses, early diagnosis and treatment can favour the prognosis (Mayer Gross 1955) and the failure to recognise three-quarters of the schizophrenics dealt with in this survey suggests that a number of other psychotic soldiers may be under treatment at their unit for depression or neurotic illness.

\section{Method}

A survey was made of the medical records and case notes of 100 consecutive male admissions treated in P Wing of Royal Victoria Hospital Netley during an eighteen month period and firmly diagnosed as suffering from schizophrenia. (Table 5). This diagnosis was made by at least two psychiatrists in each case and was confirmed by a service consultant psychiatrist.

This sample was broken down by age, rank, length of service, the military theatre in which breakdown occurred and the type of schizophrenic illness. In addition, examination was carried out of F.Med 9, F.Med 6, personal letters, reports from other hospitals and similar documents in an attempt to find the preliminary diagnosis made by the non-specialist medical officer who first saw the case and referred it for psychiatric opinion.

The records were further scrutinised to discover the chief presenting complaint, and the circumstances surrounding the patient's referral to the medical officer. In view 
of the small number of officer patients treated over this period the survey was confined to other ranks; all the patients in this sample were serving soldiers, although Netley now admits and treats Royal Navy patients. The results of the survey have been presented in tabulated form and are discussed below.

Discussion:- The average age of the 100 cases under review is 23.2 years and $88 \%$ of the cases were under 30 years of age at the time of their admission. There was an age range in this sample of from 16 years to 41 years.

Two soldiers were known schizophrenics who had been returned to duty and had broken down and a further two patients had a pre-service history of admission. Since records of information relating to these previous admissions was often incomplete or unavailable, the present admission was taken as the 'first admission' for comparative purposes.

Tredgold (1953) is of the opinion that $75 \%$ of schizophrenics are between 15 and 25 years of age when they break down and the figure in this survey is $71 \%$. Many authors have noted that paranoid schizophrenia occurs in an older age group, possibly due to a more resistant personality and the average age of the 14 paranoid schizophrenics in this sample was 32, as against an average for the remainder of 22 years. The equivalent average ages given by Kallman (1938) in a larger study are 35 years and 23 years.

Table 1 compares the percentage distribution of patients by age at first admission with those derived from the large civilian studies of Norris (1959) and the Registrar General (1955). Because of the different age range in the Army only their age-specific rates up to the age of 45 years have been used, to make a more direct comparison. However, some significance is suggested by the observations that service schizophrenics are younger on admission, and there is a very close correlation with the figures obtained by Wallis (unpublished) in a survey of Naval schizophrenics.

Table 1-Percentage distribution of patients by age at admission

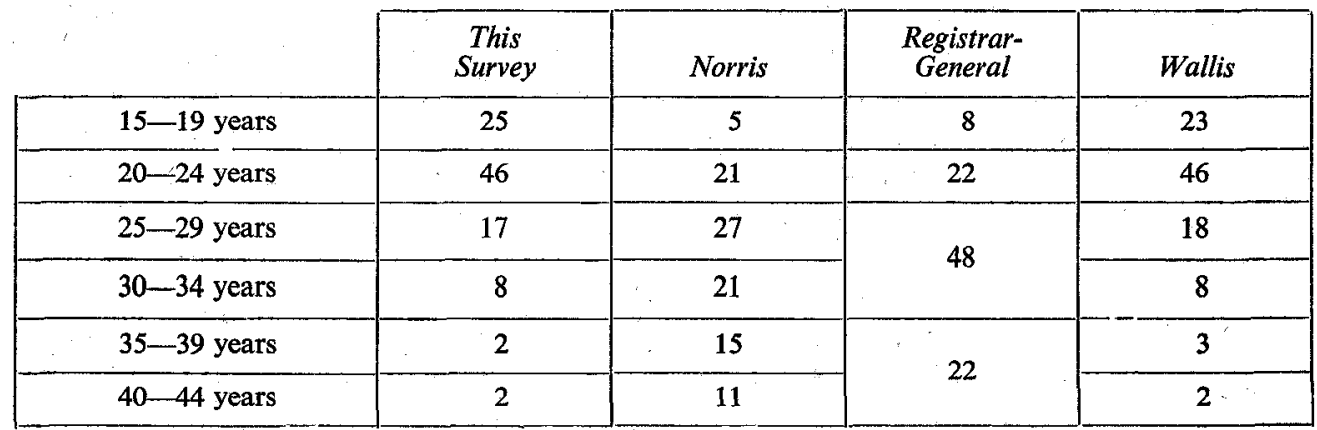

Note:- The incidence of schizophrenia in the British Army (Other Ranks) for the years 1959-1963 was 0.43 per 1,000 .

There are a number of factors which may account for this apparently earlier breakdown or recognition in a service setting. Soldiers as a group receive more frequent medical examination than their civilian counterparts, and their regular appearance before enlistment medical boards, annual Pulheems review and medical examination for special duties may be a helpful factor in early diagnosis. Some authorities acknowledge the possibility that schizophrenia may be precipitated by psychological stresses (Fish 1962) and the effect of transplantation from family security, and it is true that service psychiatrists see 
a number of acute transient schizophreniform illnesses which appear to occur in a stressful situation and to resolve spontaneously. In this connection it is possible that service life precipitates an earlier breakdown in predisposed individuals.

Table 2-Rank breakdown

\begin{tabular}{|l|c|}
\hline Rank & No. of cases \\
\hline Privates & 84 \\
L/Cpls & 8 \\
Cpls & 6 \\
Sgts & 2 \\
S/Sgts & - \\
W.Os. & - \\
& 100 \\
\hline
\end{tabular}

A further factor, which would probably have no equivalent in ordinary civilian life, is the nature of Army discipline and training which tends to focus attention on the soldier who does not conform, remains isolated from the group, or whose personal standards and response to training are unaccountably below average. Individual or rebellious behaviour, even if not grossly abnormal, is less readily tolerated in a service milieu. In addition the laws of minimal change may be operating and relatives in daily contact with a slowly developing schizophrenic may be unable to notice, or unwilling to admit, that a change in personality is occurring. Unit officers and NCOs, intent on evaluating the potential of new recruits or efficiency of old soldiers, have no preconceived ideas of the soldier's personality and are thus more readily able to pick up abnormality. Table 4 shows that $56 \%$ of the sample broke down within the first two years of their service, and nearly a quarter (21 cases) were discovered within their basic training period of six months. It may be inferred that a number of these soldiers were suffering from schizophrenia at the time of their enlistment, and it is tempting to suggest a variation of the 'drift theory' propounded by Faris and Dunham (1939)-namely that a proportion of these men had been unable to settle or hold jobs in civil employment because of their illness and had turned to the relatively constant employment offered by the Army.

Table 3 -Theatre of admission

\begin{tabular}{|l|c|}
\hline Military Theatre & No. of cases \\
\hline U.K. & 52 \\
BAOR & 33 \\
Mediterranean area & 8 \\
FARELF & 6 \\
East Africa & 1 \\
& 100 \\
\hline
\end{tabular}

Table 2 shows that $84 \%$ of the sample were private soldiers, and no allowance has been made for rank once held but lost. This would seem in accord with the average age (23. years) and length of service (3.5 years) of the sample. However, those who had obtained higher rank tended to be in the paranoid group, having achieved their promotion 
before development of the schizophrenic process at a later age, and there is a large number of long-serving privates. Allowing for the different promotion and quota standards in different corps and regiments, it is an impression that schizophrenics appear to be behind in their promotion, relative to normal soldiers.

Table 4-Length of service

\begin{tabular}{|l|c|}
\hline \multicolumn{1}{|c|}{ Length of service } & No. of cases \\
\hline Under 1 month & 5 \\
$1-3$ months & 10 \\
$3-6$ months & 6 \\
6-12 months & 12 \\
$1-2$ years & 23 \\
Over 2 years & 44 \\
& 100 \\
\hline
\end{tabular}

The number of soldiers diagnosed as suffering from schizophrenia within their first year of service is 33 (Table 4) and highlights the melancholy fact that the majority of recruits who leave the Army on medical grounds in their early training do so for psychiatric reasons (including schizophrenia). Enlistment medical boards and selection officers have not the time or opportunity to isolate the insidious, deteriorating schizophrenic, although no doubt a number of florid cases are rejected. The number of soldiers who fail to disclose a previous psychiatric history may be effectively more than the $7 \%$ discovered and this increases the difficulties of those who recruit and medically examine soldiers. The number of cases where a pre-service illness is ignored by recuiting boards must be small but experience suggests that it does happen. One remedy might be to insist on a brief medical history in writing from the recruit's general practitioner.

Table 5-Hospital Diagnosis

\begin{tabular}{|l|c|}
\hline \multicolumn{1}{|c|}{ Type of Schizophrenia } & No. of cases \\
\hline Simple schizophrenia & 19 \\
Hebephrenic schizophrenia & 22 \\
Chronic schizophrenia & 5 \\
Catatonic schizophrenia & 7 \\
Paranoid schizophrenia & 14 \\
Acute schizophrenic illness & 10 \\
Schizophrenia (type unspecified) & 23 \\
& 100 \\
\hline
\end{tabular}

Tables 7 and 8 provide a guide to the ways in which schizophrenic soldiers are brought to medical attention. In nearly three-quarters of the cases under review the patient was referred to the doctor by unit or civil authorities; this followed such disturbances as absent without leave, suicidal attempts, drunkenness or bizarre letters to authority. It appears that the authors of such correspondence are sometimes under scrutiny by their unit-one such grandiose and anonymous letter found it's way back to 
the unit of origin, where it was pithily annotated by the chief clerk, "Try Pte. J . . , , the Walter Mitty of C Coy!"'

Table 6 Referring diagnosis made by non-specialist medical Officer

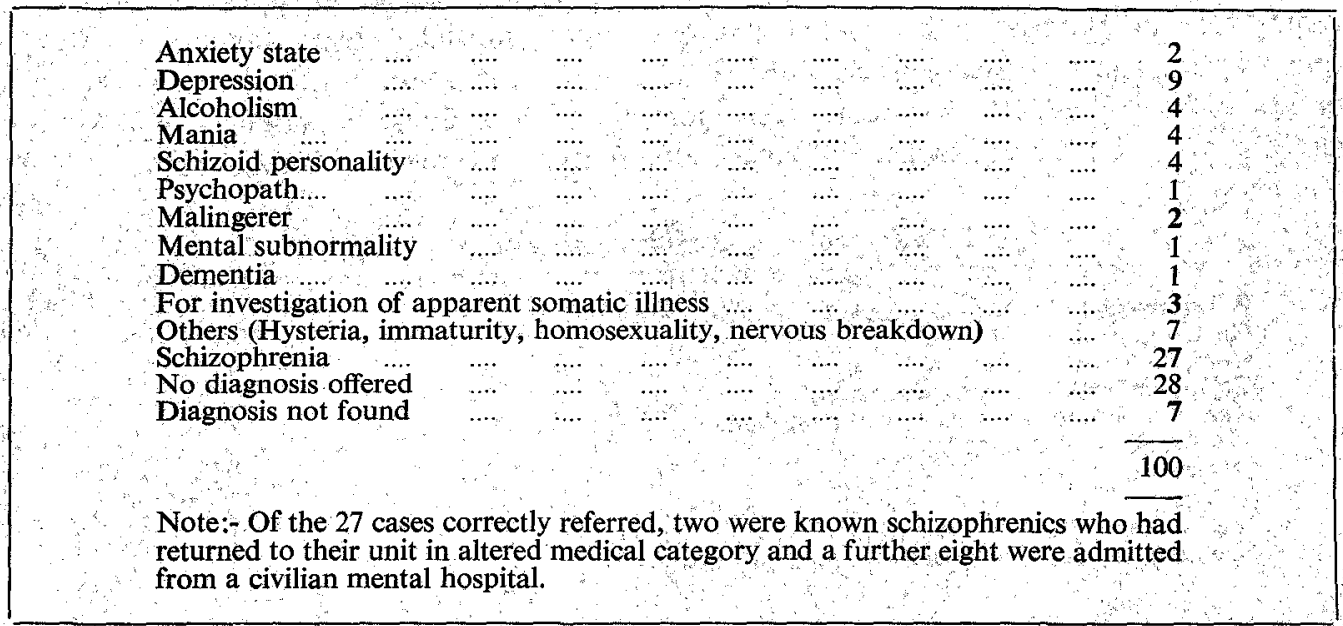

Table 7 shows that just under $50 \%$ of the sample were sent to the medical officer for opinion because of unusual behaviour within the unit, and this behaviour follows two patterns. The soldier may indulge in grossly disturbed and anti-social activities such as looking for rats in the Company Office, urinating on sleeping comrades, accusing publicans of putting drugs in their beer, masturbating in public, talking to fire-buckets or putting in a request to return to Ireland 'to find a woman' Such incidents may prove beyond the scope of the best-regulated unit and the medical officer is quickly called into action. The second type of presentation is a greater problem and it may be some time before medical opinion is sought, the unit expending a great deal of energy trying to find purely military or social reasons for the soldier's inability to respond to discipline or training. Slovenly turnout, poor personal hygiene, histrionic behaviour or deteriorating efficiency in previously reliable soldiers may suggest mental subnormality or poor motivation to the service; repeated failures to alter the soldier's habits and abilities eventually result in an appeal to the medical officer for his help in solving the problem.

Table 7 Circumstances relating to admission

Suicidal attempts

Drunkenness or increased alcohol consumption

AWOL or impulsive flight from the unit

Letters to MPs, Commanding Officers etc.

Violence, fighting or homicidal fears

Catatonic stupour

Bizarre or disturbed unit behaviour

Reduced military efficiency

Known schizophrenics (relapsed at $O P$ appointment)

Voluntary attendance at Sick Parades

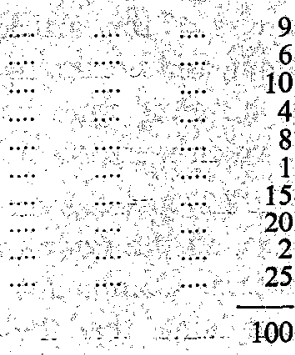

$\ldots$

20

....

(

$+$

ment) 
Only $25 \%$ of the sample reported sick to their medical officer of their own accord and Table 8 summarises the chief complaint that they voiced to the doctor-secondary symptoms or information elicited by direct questioning has not been included. Some of the presenting symptoms may have been of little value or actually led the doctor away from the diagnosis; clear-cut combinations of symptoms, pathognomonic of schizophrenia were exceptional. One soldier showed hypochondriacal fears, manifest by frequent appearances at Sick Parade with trivial complaints; a number broke down at interview or were unable to formulate clear complaints. The doctor's patience may be severely strained by the appearance of such individuals in a crowded waiting-room.

Table 8 - Patient's presenting complaint

\begin{tabular}{|c|c|c|c|}
\hline & $\begin{array}{l}\text { Fears associated with masturbation, homosexuality or VD } \\
\text { Gastro-intestinal complaints } \\
\text { Complaints referred to the limbs } \\
\text { Crying or unable to formulate a history } \\
\text { Repeated attendance with trivial complaints } \\
\text { A sensation of "change' } \\
\text { Depression } \\
\text { "Voices" } \\
\text { Ideas of reference or persecution } \\
\text { Interference or difficulty with thought processes }\end{array}$ & $\begin{array}{l}\cdots \\
\cdots \\
\cdots \\
\cdots \\
\cdots \\
\cdots \\
\cdots \\
\cdots \\
\cdots\end{array}$ & \begin{tabular}{l|l} 
\\
$\cdots$ & 4 \\
\hdashline$\cdots$ & 2 \\
$\cdots$ & 2 \\
$\cdots$ & 3 \\
$\cdots \cdots$ & 1 \\
$\cdots$ & 2 \\
$\cdots$ & 2 \\
$\cdots$ & 4 \\
$\cdots$ & 3
\end{tabular} \\
\hline
\end{tabular}

\section{After Discussion}

The firm diagnosis of schizophrenia in equivocal cases may require prolonged observation or special psychological tests by specialists familiar with the process. The difficulties involved in diagnosing (or in some cases, suspecting) the atypical case are highlighted by the present survey. Table 6 shows that only 27 patients in the sample were referred with the correct diagnosis and 10 of these cases were known or referred through a civilian mental hospital. The tone of many referring summaries is one of perplexity the feeling that the author is out of his depth. In few summaries are the salient features laid out, the differential diagnosis considered and the diagnosis made; in 29 cases the doctor was unable to offer any diagnosis, although in the majority of instances it was appreciated that the case was a psychiatric problem.

\section{Diagnosis}

This article is not intended to be critical of hard-pressed medical officers, often with limited experience of psychiatric illness. Comparable studies for trained psychiatrists seeing a case at a single interview are not available and it might be injudicious to undertake them! The aim of this article has been to show that text-book presentations are not always common and to stimulate medical officers into keeping an alert mind for such cases. Suspicion, however, must be critical to be effective and in summary it is intended to suggest cases which merit suspicion and ways in which confirmation can be obtained.

Henderson (1962) gives as one of the commonest failures to suspect schizophrenia the inability to see all the symptoms in perspective and concentrating undue attention on to one symptom. Complaints of auditory hallucinations, unrealistically paranoid attitudes and complaints that the soldier is being stared at or talked about are most 
suggestive. A sensation of 'change" or withdrawal from social contacts should arouse suspicion and frequently an admission of thought difficulty or mental turmoil can be obtained. Suicidal acts, out-of-character behaviour or a change in the efficiency and personality of a previously reliable man require explanation; in such cases, incidentally, a Wasserman reaction may occasionally be positive. A frequent presentation is with symptoms of depression or anxiety, which may only be elicited on questioning, and which persist in the absence of any clear predisposing stresses; this type of case may resist therapeutic and environmental approaches and drag on without sustained improvement. An increased consumption of alcohol may be an attempt to shake off this unaccountable depression and both may be the result of an incomplete insight, in which the patient recognises that all is not well but cannot appreciate the cause.

Once suspicion has been aroused, attention should be paid to the patient's attitude and behaviour at interview and to the rapport which it is possible to establish with him. His emotional responses may be inappropriate to his situation or frankly incongruous, and insight may be impaired. The patient may be overactive and talkative, or anergic and difficult to interview. Thought disorder or actual blocking of the train of thought may be recognised; often such patients are unable to abstract the correct meaning from simple proverbs and their definitions are discursive or they give a literal, 'concrete', interpretation. Their ability to form concepts or to extract the similarities from different situations is often impaired, and questioning about current events or simple tests of general information and knowledge can show unaccountable failures, out of keeping with the soldier's apparent intelligence. In equivocal cases evidence of minor changes in the volitional field may be most important and lead to fall of enthusiasm for sport, work or social activities, poor turnout and failure to benefit from courses of instruction, together with an increase in indecisiveness. Other valuable information may be obtained from the family history and the record of pre-service employment, or from service confidential reports. Finally, interview with a close relative may reveal that the patient's personality has altered markedly and confirm the diagnosis.

\section{Summary}

100 cases of schizophrenia treated in the Royal Victoria Hospital during an eighteenmonth period have been studied and certain findings have been tabulated, concerning age, diagnosis and circumstances relating to admission. A comparison has been made of the referring and final diagnosis and the symptoms and varieties of presentation have been considered. Some conclusions have been drawn and an attempt has been made to review these presentations as a guide to the non-specialist medical officer who is frequently the first doctor involved in the case.

\section{REFERENCES}

FARIS, R. E. L and Dunham, H. W. (1939): Mental Disorders in Urban Areas: Chicago.

FisH, F. J. (1962). Schizophrenia. Bristol.

HENDERSON, SIR DAVID and BATCHELOR, I. C. (1962) Textbook of Psychiatry. Oxford Univ. Press.

HILL, D. (1963). Brit. Med. J. 2.581.

KALLMAN, F. J. (1938). The Genetics of Schizophrenia. New York.

MAYOR-GROSS, W. With SLATER, E. and ROTH, M. (1955), Clinical Psychiatry. London.

NoRRIS, V. (1959). Mental Illness in London. Oxford Univ. Press.

REGISTRAR-GENERAL (1955). Statistical Review of England and Wales for 1950-1951 (supplement on General Morbidity, Cancer and Mental Health. H.M.S.O.

TREDGold, A. F. and TREDGold, R. F. (1953). Manial of Psychological Medicine. Ballière, Tindall and Cox, London.

VICKERS, SIR GEOFFREY (1965). Lancet 1: 1021 . 